\title{
A possible connection between adhesion regulating molecule 1 overexpression and nuclear factor kappa $B$ activity in hepatocarcinogenesis
}

\author{
XIN YANG $^{1}$, XIONGYING MIAO $^{1}$, YU WEN $^{1}$, JIXIONG HU ${ }^{1}$, WEIDONG DAI ${ }^{1}$ and BANGLIANG YIN ${ }^{2}$ \\ Departments of ${ }^{1}$ General Surgery, and ${ }^{2}$ Cardiothoracic Surgery, the Second Xiangya Hospital, \\ Central South University, Changsha, Hunan Province 410011, P.R. China
}

Received January 9, 2012; Accepted February 21, 2012

DOI: $10.3892 /$ or.2012.1767

\begin{abstract}
Adhesion regulating molecule 1 (ADRM1), a 19S proteasome cap-associated protein, and nuclear factor kappa $\mathrm{B}$ $(\mathrm{NF}-\kappa \mathrm{B})$, a protein transcription factor controlling DNA transcription, may play an important role in tumorigenesis. Overexpression of ADRM1 and activation of NF- $\kappa \mathrm{B}$ are wellobserved in hepatocellular carcinoma (HCC). However, little is known about whether both are functionally connected during hepatocarcinogenesis, and the mechanisms involved. In this study, using laboratory techniques including short hairpin RNA (shRNA)-mediated knockdown, immunohistochemistry (IHC), both semi-quantitative and real-time RT-PCR, western blotting, MTT assay, transwell assay, flow cytometry and electrophoretic mobility shift assay (EMSA), the expression of ADRM1, the effects of ADRM1 knockdown on NF- $\kappa$ B activity, as well as the biological behavior of HCC cells including proliferation, migration, invasion and apoptosis were investigated in the samples from HCC patients and HCC cell lines. We found that both mRNA and protein levels of ADRM1 were increased in HCC tissues and that this increase in ADRM1 expression was parallel to the metastatic potential of HCC cell lines. After ADRM1 knockdown in MHCC97-H cells, the expression of I $\kappa$ B- $\alpha$ was increased and the NF- $\kappa \mathrm{B}$ activity was reduced. Furthermore, ADRM1 knockdown inhibited MHCC97-H cell proliferation and induced cell apoptosis, and the migration and invasion of MHCC97-H cells were significantly repressed. These results indicate that there is a clear functional connection between ADRM1 and NF- $\mathrm{BB}$ in hepatocarcinogenesis, despite the precise mechanisms through which the two work together still being unknown.
\end{abstract}

Correspondence to: Professor Xiongying Miao, Department of General Surgery, the Second Xiangya Hospital, Central South University, 139 Renmin Middle Road, Changsha, Hunan Province 410011, P.R. China

E-mail: miaoxiongying58@hotmail.com

Key words: hepatocellular carcinoma, adhesion-regulating molecule 1, overexpression, short hairpin RNA, nuclear factor kappa B

\section{Introduction}

Adhesion-regulating molecule 1 (ADRM1), a 19S proteasome cap-associated protein that recruits the deubiquitinating enzyme $\mathrm{UCH} 37$ to the $26 \mathrm{~S}$ proteasome (1-4), has been recognized as a novel ubiquitin receptor (5). ADRM1 is widely involved in cell biological processes such as differentiation, migration, and adhesion (6-8). It is crucial for spermatogenesis and oogenesis in mammals (9). Accumulating evidence has suggested that ADRM1 may hold an important role in tumorigenesis as well. Studies show that ADRM1 is commonly overexpressed in tumors of different sources including liver, lung, colon, bladder, kidney, stomach and ovary $(10,11)$. ADRM1 is also identified as an amplification target in ovarian cancer, and its overexpression is significantly associated with earlier recurrence and worse survival (12).

Nuclear factor kappa B $(\mathrm{NF}-\kappa \mathrm{B})$, which is a protein transcription factor controlling DNA transcription, plays a key role in immune response and is involved in tumorigenesis of many types of cancer (13-15). In quiescent cells, $N F-\kappa B$ normally stays in an inactive form in the cytoplasm by interacting with inhibitors of $\kappa \mathrm{B}(\mathrm{I} \kappa \mathrm{Bs})$ that mask its nuclear localization sequence (16). Under some pathological conditions, such as cancer, aberrant constitutive NF- $\kappa \mathrm{B}$ activation occurs. This abnormality is mainly attributed to malfunction of $\mathrm{I} \kappa \mathrm{B}-\alpha(15)$. Persistent $\mathrm{NF}-\kappa \mathrm{B}$ activation has been observed in hepatocellular carcinoma (HCC) (16-18). It has been regarded as an important step in hepatocarcinogenesis $(19,20)$. However, whether ADRM1 has any functional connections with $\mathrm{NF}-\kappa \mathrm{B} / \mathrm{I} \kappa \mathrm{B}$ as regards hepatocarcinogenesis is still poorly known.

In this study, using the samples from $\mathrm{HCC}$ patients and $\mathrm{HCC}$ cell lines, the expressions of ADRM1, the effects of ADRM1 knockdown on NF- $\kappa$ B activity, as well as the biological behavior of HCC cells, including proliferation, migration, invasion and apoptosis, were investigated collectively, which would help obtain further insight into the role of ADRM1 and NF- $\kappa \mathrm{B} / \mathrm{I} \kappa \mathrm{B}$ in the pathogenesis of $\mathrm{HCC}$.

\section{Materials and methods}

Human HCC samples. Specimens of HCC tissues and their adjacent non-tumor liver tissues were obtained from 68 primary HCC patients who underwent hepatectomy at our department 
from November 2010 to May 2011. None of the patients had received either chemotherapy or radiotherapy before surgery, and their diagnoses were confirmed by histological examinations. The clinicopathologic features of these patients are shown in Table I. All of the 68 samples were analyzed by immunohistochemical assays. Among them, specimens from 30 cases were collected, immediately frozen in liquid nitrogen, and stored at $-80^{\circ} \mathrm{C}$ for quantitative real-time RT-PCR analysis. The study protocol was approved by the Human Ethics Review Committee of Central South University and a prior informed consent was obtained from each patient for the collection of liver specimens. All specimens were handled and made anonymous according to the ethical and legal standards.

Cell culture. Hep3B cells were purchased from American Type Culture Collection (ATCC, USA). MHCC97-L and MHCC97-H cells were obtained from the Liver Cancer Institute of Fudan University (Shanghai, China). Cells were cultured in Dulbecco's modified Eagle's medium (DMEM) containing $10 \%$ fetal bovine serum at $37^{\circ} \mathrm{C}$ in a humidified atmosphere containing $5 \% \mathrm{CO}_{2}$.

RNA isolation and semi-quantitative RT-PCR. The mRNA expression levels of ADRM1 in Hep3B, MHCC97-L and MHCC97-H cells were examined by RT-PCR. Total RNA was isolated from tissue specimens and HCC cell lines using TRIzol reagent (Invitrogen, USA) according to the manufacturer's instructions. The quality of RNA was verified by the OD260/ OD280 ratio. First-strand cDNA was synthesized from $2 \mu \mathrm{g}$ of total RNA using oligo(dT) $)_{18}$ primer and the RevertAid ${ }^{\mathrm{TM}} \mathrm{H}$ Minus First Strand cDNA Synthesis kit (Fermentas, Canada). Semi-quantitative RT-PCR was performed using the PCR Master Mix (2X) (Fermentas, USA) according to the manufacturer's protocols. The following primers were used: ADRM1 (expected fragment size 164 bp), 5'-AAGTACTTGGTGGAGTTTCG-3' (forward), and 5'-ATGATCAAGTCGTCTTCCAC-3' (reverse); GAPDH (expected fragment size 450 bp), 5'-ACCACAGTCCAT GCCATCAC-3' (forward), and 5'-TCCACCACCCTGTTGC TGTA-3' (reverse). The PCR program consisted of an initial denaturation step $\left(95^{\circ} \mathrm{C}\right.$ for $\left.5 \mathrm{~min}\right)$, followed by 40 cycles of amplification (denaturation at $94^{\circ} \mathrm{C}$ for $30 \mathrm{sec}$, primer annealing at $55^{\circ} \mathrm{C}$ for $30 \mathrm{sec}$, product elongation at $72^{\circ} \mathrm{C}$ for $30 \mathrm{sec}$ ), and a termination step $\left(72^{\circ} \mathrm{C}\right.$ for $\left.5 \mathrm{~min}\right)$. The amplified products were electrophoresed on $2 \%$ agarose gels and visualized by ethidium bromide staining. The gel optical density analysis software (Gel-Pro 4.0) was used to scan and calculate integral optical density (IOD) of strips. The relative mRNA expressions of ADRM1 were represented as a ratio of ADRM1-IOD and GAPDH-IOD.

Real-time RT-PCR. ADRM1 mRNA expressions in 30 pairs of $\mathrm{HCC}$ tissues and adjacent non-tumor liver tissues were evaluated by real-time RT-PCR. The reactions were performed using the Green PCR Master Mix (Applied Biosystems, USA) on a 7900HT Fast Real-Time PCR System (Applied Biosystems). RNA isolation and cDNA synthesis were the same as mentioned above. The following primers were used: ADRM1,5'-AAGTACT TGGTGGAGTTTCG-3' (forward), and 5'-ATGATCAAGTCG TCTTCCAC-3' (reverse); GAPDH, 5'-CAATGACCCCTTCAT TGACC-3' (forward), and 5'-GACAAGCTTCCCGTTCTCAG-3' (reverse). The real-time PCR program consisted of an initial
Table I. Relationship between ADRM1 expression and clinicopathological parameters in HCC tissues.

\begin{tabular}{lcccc}
\hline & \multicolumn{5}{c}{ Expression of ADRM1 } \\
\cline { 2 - 5 } Parameter & No. of cases & Low & High & P-value \\
\hline Age & 36 & 17 & 19 & NS \\
$\geq 60$ years & 32 & 18 & 14 & \\
$<60$ years & & & & \\
Gender & 56 & 29 & 27 & NS \\
Male & 12 & 6 & 6 & \\
Female & & & &
\end{tabular}

$\begin{array}{lllll}\text { Tumor size } & & & & \\ \leq 5 \mathrm{~cm} & 30 & 12 & 18 & \text { NS } \\ >5 \mathrm{~cm} & 38 & 23 & 15 & \end{array}$

$\begin{array}{lllll}\text { Histologic grade } & & & & \\ \text { Well/mod } & 41 & 24 & 17 & \text { NS } \\ \text { Poor } & 27 & 11 & 16 & \end{array}$

$\begin{array}{lrrrr}\begin{array}{l}\text { AFP } \\ \leq 400 \mathrm{ng} / \mathrm{ml}\end{array} & 33 & 17 & 16 & \mathrm{NS} \\ >400 \mathrm{ng} / \mathrm{ml} & 35 & 18 & 17 & \\ & & & & \\ \text { HBsAg } & & & & \\ \text { Negative } & 14 & 6 & 8 & \text { NS } \\ \text { Positive } & 54 & 29 & 25 & \end{array}$

No. of tumors

$\begin{array}{lllll}\text { Solitary } & 42 & 19 & 23 & \text { NS } \\ \text { Multiple } & 26 & 16 & 10 & \end{array}$

Capsular formation

$\begin{array}{rrrrr}\text { Yes } & 52 & 25 & 27 & \text { NS } \\ \text { No } & 16 & 10 & 6 & \end{array}$

Liver cirrhosis

$\begin{array}{lrrrr}\text { Yes } & 49 & 27 & 22 & \text { NS } \\ \text { No } & 19 & 8 & 11 & \end{array}$

Venous invasion

$\begin{array}{lrrrr}\text { Yes } & 14 & 2 & 12 & 0.002 \\ \text { No } & 54 & 33 & 21 & \end{array}$

NS, not significant; well, well differentiated; mod, moderately differentiated; poor, poorly differentiated.

denaturation step ( $95^{\circ} \mathrm{C}$ for $5 \mathrm{~min}$ ) and 40 cycles of amplification (denaturation at $94^{\circ} \mathrm{C}$ for $20 \mathrm{sec}$, primer annealing at $59^{\circ} \mathrm{C}$ for $20 \mathrm{sec}$ and product elongation at $72^{\circ} \mathrm{C}$ for $20 \mathrm{sec}$ ). The specificity of amplified products was checked by melting curve analysis. Data were calculated with the $2^{-\Delta \Delta C t}$ method, which is a conve- 
nient way to analyze the relative changes in gene expression from real-time RT-PCR $(21,22)$, and expressed as relative expression (RQ value) of transcripts normalized to GAPDH.

Immunohistochemistry. Immunohistochemistry (IHC) was performed on deparaffinized and rehydrated formalin-fixed paraffin sections to determine the protein expression of ADRM1 in 68 cases of HCC tissues and adjacent non-tumor liver tissues. Antigen retrieval was carried out by immersing the sections in the citrate buffer ( $\mathrm{pH}$ 6.0) and heating them at $100^{\circ} \mathrm{C}$ in a microwave oven for $6 \times 2 \mathrm{~min}$. Endogenous peroxidase activity was blocked by incubating the sections in methanol containing $0.3 \%$ hydrogen peroxide for $10 \mathrm{~min}$. After pretreatment with $10 \%$ normal goat serum, the slides were incubated with primary antibody against ADRM1 (1:100 dilution; Proteintech Group, Chicago, IL, USA) at $4^{\circ} \mathrm{C}$ overnight, and subsequently, with HRP-conjugated secondary antibody at room temperature for $1 \mathrm{~h}$. Sections were then stained with 3,3'-diaminobenizidine, counterstained with hematoxylin, dehydrated, and mounted in Permount. As a negative control, PBS was used instead of the primary antibody. Immunoreactivity was evaluated independently by two observers, who were blinded to the patients clinicopathologic data. The staining intensities were scored as: none, weak, moderate, and strong, as previously described (12). Discrepancies were rechecked and final decisions were reached by consensus. For statistical analysis, ADRM1 expression was classified into two groups: low expression was defined as none or weak staining, and high expression was defined as moderate or strong staining.

Western blot analysis. Cells were harvested, washed with cold PBS and then lysed by incubating with the cell lysis buffer (Beyotime, China) for $30 \mathrm{~min}$ on ice. Cell lysates were cleared by centrifugation and supernatant was collected. Nuclear protein extracts were prepared with the NucBuster ${ }^{\mathrm{TM}}$ Protein Exaction kit (Merck Biosciences, Germany) according to the manufacturer's protocols. Protein concentration was determined by using a BCA kit (Beyotime, China). To evaluate the protein expression of ADRM1, I $\kappa$ B- $\alpha$ and nuclear NF- $\kappa$ B p65 in HCC cells, Western blot assays were performed. Equal amounts of proteins that were obtained from whole cell lysis or nuclear extracts were resolved by $10 \%$ SDS-PAGE, and transferred to PVDF membranes (Pierce Biotechnology, USA). The membranes were blocked with $5 \%$ non-fat dry milk in PBS $\left(37^{\circ} \mathrm{C}\right.$ for $\left.2 \mathrm{~h}\right)$, and incubated with primary antibodies as follows: rabbit polyclonal ADRM1 antibody (1:300 dilution; Proteintech Group), rabbit polyclonal I $\mathrm{B}-\alpha$ antibody (1:500 dilution; Santa Cruz Biotechnology, Santa Cruz, USA), rabbit polyclonal NF-кB p65 antibody (1:500 dilution; Cell Signaling Technology, Beverly, MA, USA), rabbit monoclonal GAPDH antibody (1:1000 dilution; Cell Signaling Technology, Danvers, MA, USA) and rabbit polyclonal histone H2A.X antibody (1:400 dilution, Cell Signaling Technology, Beverly, MA, USA) at $4^{\circ} \mathrm{C}$ overnight. After washing, the membranes were incubated with HRP-conjugated secondary antibodies (goat anti-rabbit IgG, 1:5000 dilution; Santa Cruz Biotechnology) and the immunolabeled proteins were detected by enhanced chemiluminescence (ECL). The film was scanned, and the image was analyzed with Gel-Pro 4.0. The relative levels of target protein were represented as the ratio of target proteinIOD and GAPDH-IOD (for ADRM1 and I $\mathrm{B}-\alpha$ from whole cell lysis) or histone H2A.X-IOD (for NF- $\kappa \mathrm{B}$ p65 from nuclear extracts).

Construction of short hairpin RNA (shRNA) expression plasmids. Specific sequences used to knock down ADRM1 and a scrambled sequence used as negative control (shNC) were synthesized by GenePharma Corp. (Shanghai, China), and were subcloned into pGPU6/GFP/Neo-shRNA expression vectors (Genepharma, China). BLAST analysis indicated that none of these sequences have any homology with other human genes. The sequences of the oligonucleotides were as follows (the underlined sequence targeting ADRM1, the bold letters indicating the loop sequence): ADRM1-204 (nt204-224); sense 5'-CACCGGAAAGGGCTGGTGTACATTCTTCAAGAGA GAATGTACACCAGCCCTTTCCTTTTTTG-3', antisense 5'-GATCCAAAAAAGGAAAGGGCTGGTGTACATTCTCT CTTGAAGAATGTACACCAGCCCTTTCC-3'. ADRM1-351 (nt351-371); sense 5'-CACCGGGTCTACGTGCTGAAGTTCA TTCAAGAGATGAACTTCAGCACGTAGACCCTTTTTT G-3', antisense 5'-GATCCAAAAAAGGGTCTACGTGCTGA AGTTCATCTCTTGAATGAACTTCAGCACGTAGACCC-3'. ADRM1-1046 (nt1046-1066); sense 5'-CACCGCGGATGAG ATCCAGAATACCTTCAAGAGAGGTATTCTGGATCTCA TCCGCTTTTTTG-3', antisense 5'-GATCCAAAAAAGCGG ATGAGATCCAGAATACCTCTCTTGAAGGTATTCTGG ATCTCATCCGC-3'. shNC; sense 5'-CACCGTTCTCCGA ACGTGTCACGTCAAGAGATTACGTGACACGTTCGGAG

AATTTTTTG-3', antisense 5'-GATCCAAAAAATTCTCCG AACGTGTCACGTAATCTCTTGACGTGACACGTTCGGA GAAC-3'. The 5' ends of the sense and antisense templates were compatible with the overhang regions generated by digesting the pGPU6/GFP/Neo-shRNA vector with restriction enzymes BbsI and BamHI. The T6 sequence served as a termination signal. The recombinant plasmids were identified by sequencing (Invitrogen Biotechnology, China).

Transfection of the shRNA expression plasmids. For transient transfection, MHCC97-H cells were placed into 6-well culture plates at a concentration of $5 \times 10^{4}$ cells per well and incubated overnight. Cells were transfected using Lipofectamine 2000 reagent (Invitrogen, USA) according to the manufacturer's instructions. Forty-eight hours after transfection, real-time RT-PCR and Western blot were conducted to evaluate the efficiency of ADRM1 knockdown.

MTT assay. Cell proliferation was assessed by MTT assay. In brief, cells were harvested and seeded in a 96-well plate ( $1 \times 10^{4}$ cells per well), then, transfected with shRNA expression plasmids and were allowed to grow for 24, 48 and $72 \mathrm{~h}$ at $37^{\circ} \mathrm{C}$ with $5 \% \mathrm{CO}_{2}$. MTT (Keygen, China) and DMSO were then added, and the absorbance at $570 \mathrm{~nm}$ was measured with a model 680 microtiter plate reader (Bio-Rad, USA). The MTT assays were performed in triplicate. Cell growth curves were calculated as mean values for each group.

Apoptosis analysis by flow cytometry. Cell apoptosis was assessed by flow cytometry using an annexin V-FITC/propidium iodide (PI) apoptosis detection kit (Keygen, China). Briefly, cells were trypsinized, washed, re-suspended in a binding buffer at a concentration of $1 \times 10^{6}$ cells $/ \mathrm{ml}$, and then stained with annexin-V 
and PI. After incubation for 15 min at room temperature in the dark, cells were analyzed by flow cytometry with FACS Aria (BD Biosciences, USA). Assays were replicated three times. Cells that were annexin-V-positive and PI-negative were considered as early apoptotic while annexin V-positive and PI-positive ones were classified as late apoptotic cells (23).

In vitro invasion and migration assays. Invasion assays were performed using transwell chambers (Corning, USA, pore size $8 \mu \mathrm{m}$ ) coated with matrigel (BD Biotechnology, USA). Forty-eight hours after transfection, the cells were suspended in serum-free medium containing $5 \%$ BSA at a density of $5 \times 10^{4} / \mathrm{ml}$. Then the cell suspension $(2 \mathrm{ml})$ was added into the upper compartment of the transwell, and the lower chamber was filled with 10\% FBS medium. After $24 \mathrm{~h}$ of incubation, cells were fixed with $95 \%$ ethanol and stained with hematoxylin-eosin. Invading cells were counted from five randomly selected fields (at magnification $\mathrm{x} 250$ ). Migration assays were conducted as described above but without matrigel. Three independent experiments were done for each assay.

Electrophoretic mobility shift assay (EMSA). To detect the DNA-binding activity of NF- $\mathrm{KB}$, EMSA was performed with a LightShift Chemiluminescent EMSA kit (Pierce). A doublestranded NF- $\kappa$ B probe (sense sequence: 5'-AGTTGAGGGGACT TTCCCAGGC-3') was purchased from Beyotime Biotechnology (Haimen, China). The biotin-labeled probe $(0.5 \mu \mathrm{l})$ was incubated with $10 \mu \mathrm{g}$ nuclear protein extracts in a binding buffer. The reaction mixture was separated on a $0.5 \mathrm{X}$ TBE polyacrylamide gel, transferred to a nylon membrane (Amersham Biosciences, Sweden), and then UV cross-linked. Signals were detected by streptavidin-HRP conjugate. Labeled probe without protein was used as a negative control, and HeLa cell nuclear extracts served as a positive control.

Statistical analysis. Statistical analysis was performed with SPSS version 13.0 (SPSS Inc., Chicago, IL, USA). Data were expressed as mean $\pm \mathrm{SD}$. The correlation between ADRM1 expression and clinicopathological variable was analyzed by $\chi^{2}$ test. Differences between two groups were evaluated by t-test. Differences between multiple groups were assessed by one-way ANOVA test. $\mathrm{P}<0.05$ was considered statistically significant.

\section{Results}

ADRM1 expression was up-regulated in HCC. Compared to matched non-tumor liver tissues, ADRM1 mRNA expression levels in HCC tissues were significantly elevated (Fig. 1A, $\mathrm{P}<0.05)$. To further investigate the properties of ADRM1 expression in HCC, we performed IHC analysis on a series of $68 \mathrm{HCC}$ tissues and adjacent non-tumor liver tissues. Positive labeling for ADRM1 was localized mainly in the nucleus, and partially in the surrounding cytoplasm (Fig. 1B). The high expression of ADRM1 was more frequently detected in HCC tissues (33/68, $49 \%$ ) than in adjacent non-tumor liver tissues $(6 / 68,9 \%)$. Positive correlations between ADRM1 expression and venous invasion was also observed (Table I, $\mathrm{P}=0.002$ ).

ADRM1 expression was up-regulated corresponding to the metastatic potential of HCC cell lines. RT-PCR and Western
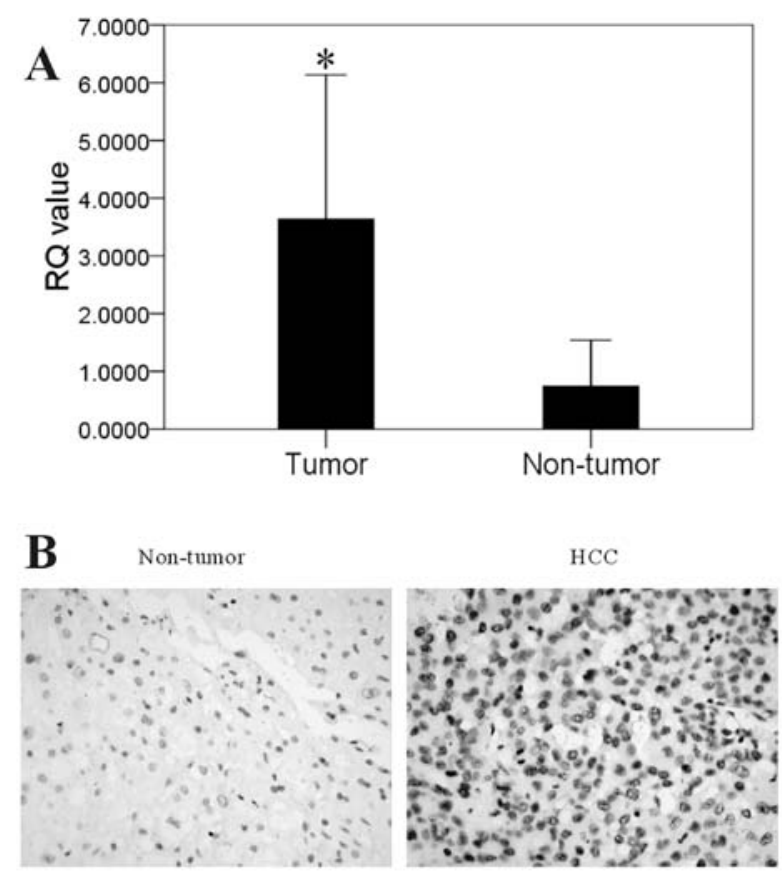

Figure 1. Expression of ADRM1 in primary HCC. (A) ADRM1 mRNA levels in 30 human $\mathrm{HCC}$ tissues and their matched non-tumor liver tissues were evaluated by real-time RT-PCR. ADRM1 mRNA levels in HCC tissues were significantly elevated compared with non-tumor liver tissues ( $\mathrm{P}<0.05$ vs non-tumor tissue) (B) Representative immunostaining images for ADRM1 in human HCC tissues and adjacent non-tumor liver tissues (at magnification x200).

blot analyses were performed for detecting the expression levels of ADRM1 in Hep3B, MHCC97-L and MHCC97-H cells, which have non-, high and higher metastatic capacities, respectively (24). Results showed that both ADRM1 mRNA and protein levels increased stepwise in accordance with their metastatic potential (Fig. 2A and B). To test whether suppressing ADRM1 in HCC cells could reduce their oncogenic potential, shRNAmediated ADRM1 knockdown was performed in MHCC97-H cells that expressed the highest level of ADRM1. Real-time RT-PCR analysis showed that all three of the ADRM1 shRNA plasmids (namely, pGPU6/GFP/Neo-ADRM1-204, pGPU6/ GFP/Neo-ADRM1-351 and pGPU6/GFP/Neo-ADRM1-1046) down-regulated ADRM1 mRNA, while the plasmid pGPU6/ GFP/Neo-ADRM1-351 caused the greatest reduction of ADRM1 mRNA level (Fig. 2C). Western blot analysis consistently demonstrated that this plasmid significantly suppressed ADRM1 protein expression (Fig. 2D). Thereby, the plasmid pGPU6/GFP/ Neo-ADRM1-351 was selected for subsequent experiments.

Knockdown of ADRM1 suppressed proliferation, invasion and migration of MHCC97-H cells and induced cell apoptosis. At 48 and $72 \mathrm{~h}$ after transfection, the ADRM1 shRNA-transfected cells had a significantly reduced proliferation level compared with the untransfected cells (Fig. 3, P<0.05). The number of migrated cells decreased significantly in the ADRM1 shRNAtransfected cells (Fig. 4A, P<0.05). ADRM1 knockdown also significantly reduced the number of invading cells (Fig. 4B, $\mathrm{P}<0.05)$. No significant differences between the untransfected and shNC-transfected cells were observed.

The percentage of early apoptotic cells and late apoptotic ones was significantly increased in the ADRM1 knockdown 
A

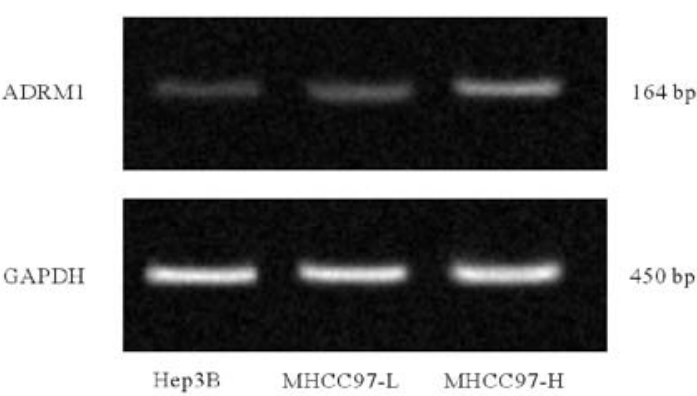

Hep3B MHCC97-L MHCC97-H

B

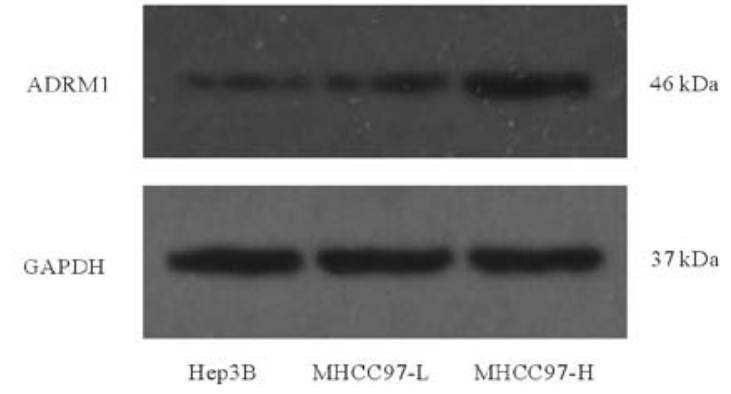

C

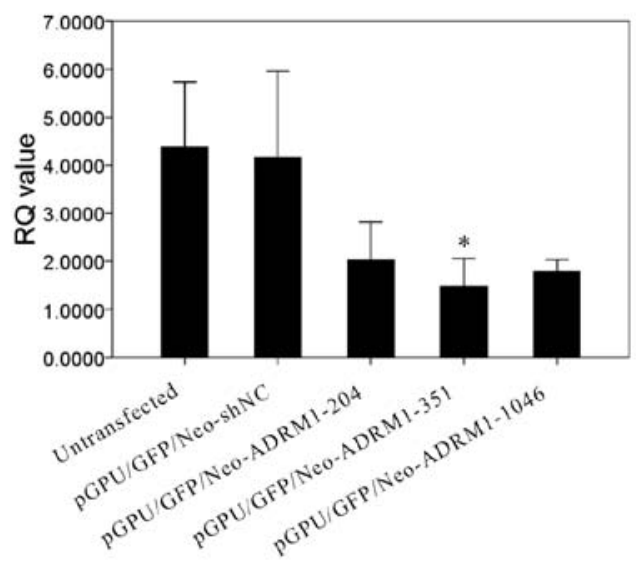

D

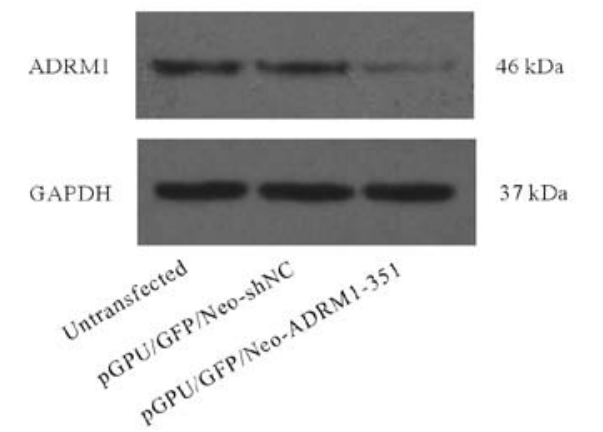

Figure 2. ADRM1 expression in HCC cell lines and the suppression by shRNA. (A) RT-PCR analysis of ADRM1 mRNA levels. (B) Western blot analysis of ARDM1 protein levels. (C) ADRM1 mRNA levels in untransfected and transfected MHCC97-H cells, as evaluated by real-time RT-PCR. The plasmid pGPU6/ GFP/Neo-ADRM1-351 showed the most efficient suppression of ADRM1 mRNA. * $<<0.05$ vs all the others. (D) Western blot analysis confirmed that the plasmid pGPU6/GFP/Neo-ADRM1-351 down-regulated ADRM1 protein expression in MHCC97-H cells.

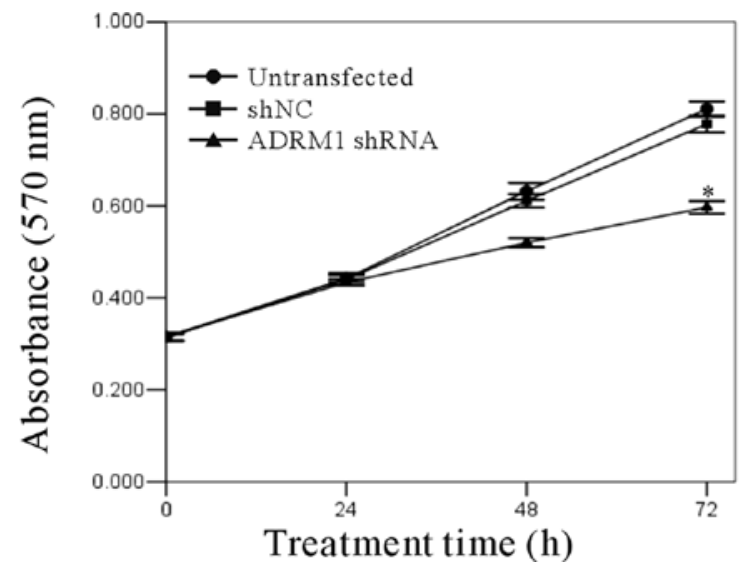

Figure 3. Inhibitory effects of ADRM1 knockdown on the proliferation of MHCC97-H cells. At 48 and $72 \mathrm{~h}$ after transfection, the proliferation levels of shRNA-transfected MHCC97-H cells were significantly lower than that of parental cells, as measured by MTT assays. ${ }^{*} \mathrm{P}<0.05$ vs untransfected cells.

group (Fig. 5, $\mathrm{P}<0.05$ ). Again, no significant difference was observed between the untransfected and shNC-transfected cells.

ADRM1 was responsible for increased $N F-\kappa B$ activity in $H C C$ cells. To explore the relationship between ADRM1 and NF- $\kappa \mathrm{B}$, we first analyzed protein levels of nuclear NF- $\kappa$ B p65 and I $\kappa$ B- $\alpha$ in Hep3B, MHCC97-L and MHCC97-H cells. Western blot analysis revealed that nuclear $\mathrm{p} 65$ expression increased in these 3 cell lines, following the pattern of their ADRM1 levels, with Hep3B having the lowest, and MHCC97-H the highest nuclear p65 levels. In contrast, I $\kappa$ B- $\alpha$ expression showed an opposite tendency (Fig. 6A). ADRM1 knockdown by ADRM1 shRNA transfection of MHCC97-H cells inhibited nuclear p65 expression; on the contrary, IкB- $\alpha$ expression was elevated (Fig. 6B). Furthermore, EMSA assay showed that the DNA-binding activity of NF- $\kappa$ B in MHCC97-H cells was reduced by ADRM1 knockdown (Fig. 6C).

\section{Discussion}

Although ADRM1 may be tumorigenic, more details regarding its roles in the cell biology of HCC are still required. In this study, we confirmed that both mRNA and protein levels of ADRM1 were significantly higher in HCC tissues than in non-tumor liver tissues. That is in line with another report (10). A positive correlation between ADRM1 expression in HCC tissues and venous invasion of HCC, which was checked by clinical pathology, was also found in this study. Similar results were found in vitro, in which ADRM1 expression was increased in parallel with the metastatic potential of HCC cell lines. Furthermore, by knockdown of ADRM1 using RNA interference technology, we found that suppression of ADRM1 expression inhibited MHCC97-H cell proliferation and induced cell apoptosis, and the migration and invasion of MHCC97-H cells were significantly repressed. These findings imply that overexpression of ADRM1 may represent a metastatic character, and plays an oncogenic role in the progression of HCC. Likewise, ADRM1 overexpression has been found significantly related to metastasis of breast carcinoma cells (6), ovarian cancer (12) and colorectal cancer (25). 
A

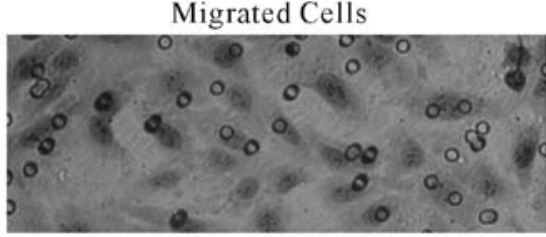

Untransfected

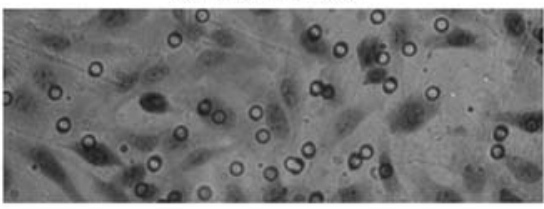

$\operatorname{shNC}$

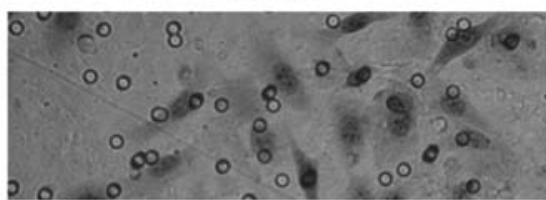

ADRM1 shRNA

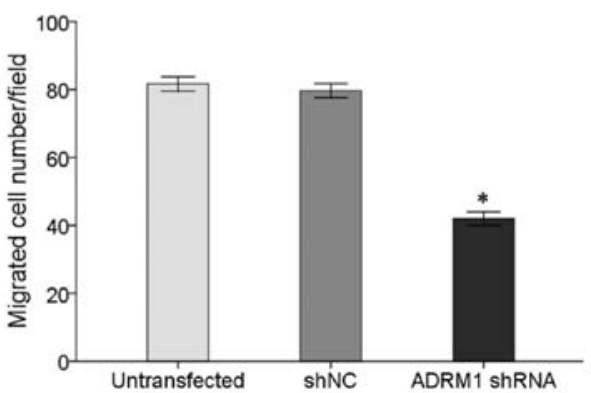

B

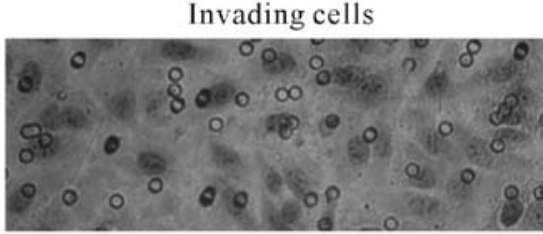

Untransfected

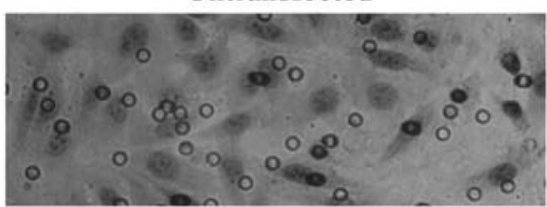

$\operatorname{shNC}$

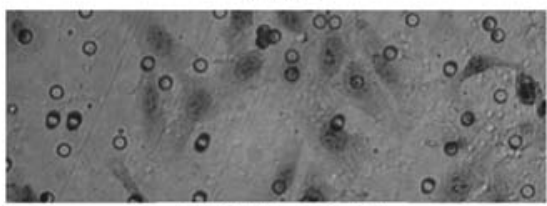

ADRMl shRNA

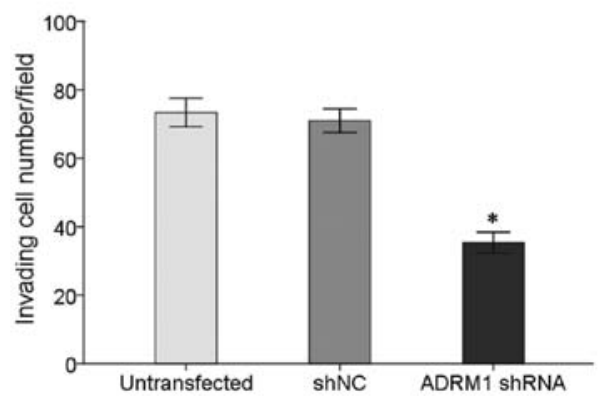

Figure 4. ADRM1 knockdown inhibited MHCC97-H cell migration and invasion. (A) The number of migrated cells significantly decreased in shRNA-transfected cells. (B) The number of invading cells significantly decreased in shRNA-transfected cells. "P<0.05 vs untransfected cells.

A
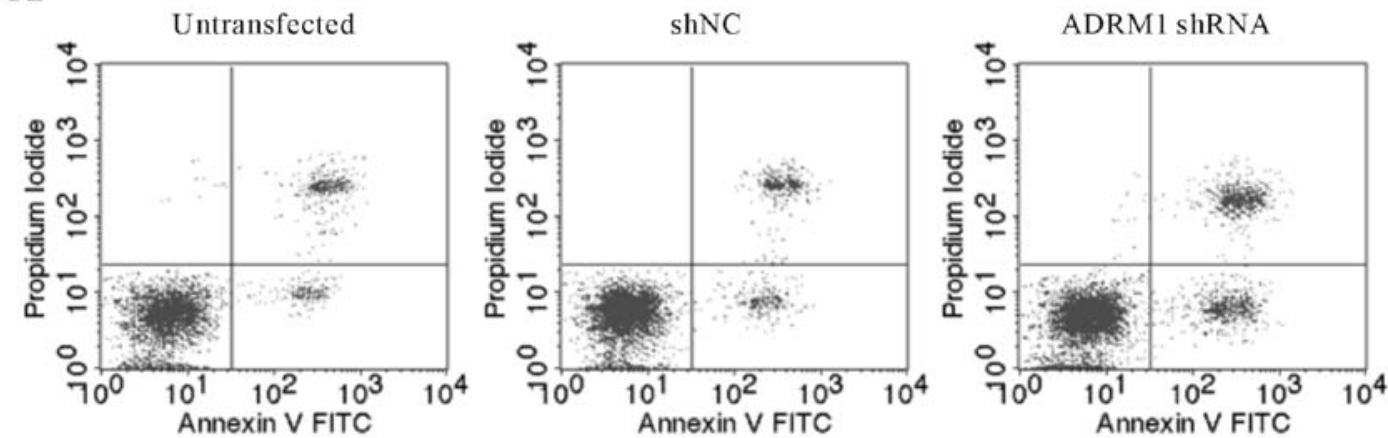

B

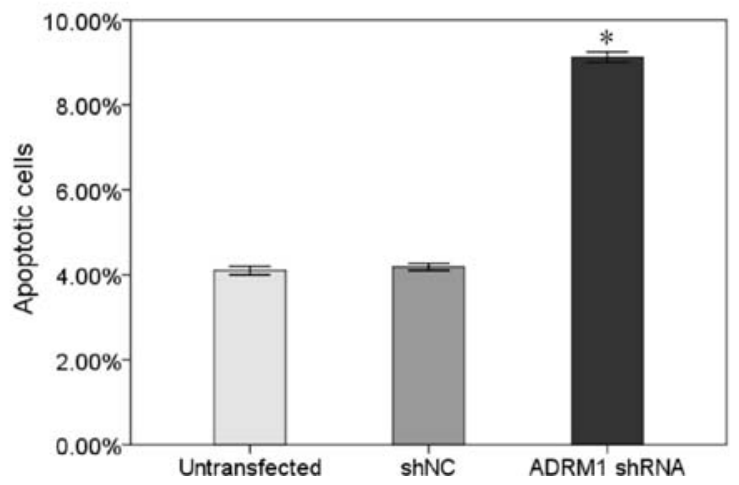

Figure 5. ADRM1 knockdown induced MHCC97-H cell apoptosis. (A) Cell apoptosis was assessed by annexin-V/PI analysis. (B) Apoptotic rate in shRNAtransfected MHCC97-H cells significantly increased compared with untransfected cells. " $\mathrm{P}<0.05$ vs untransfected cells. 


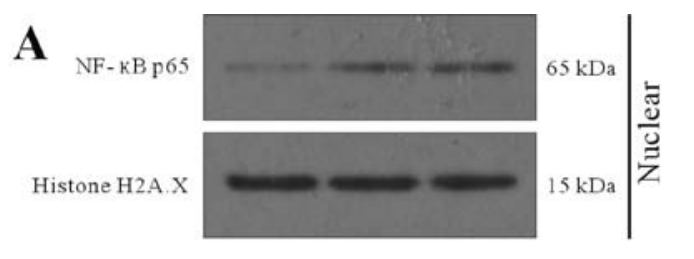

C
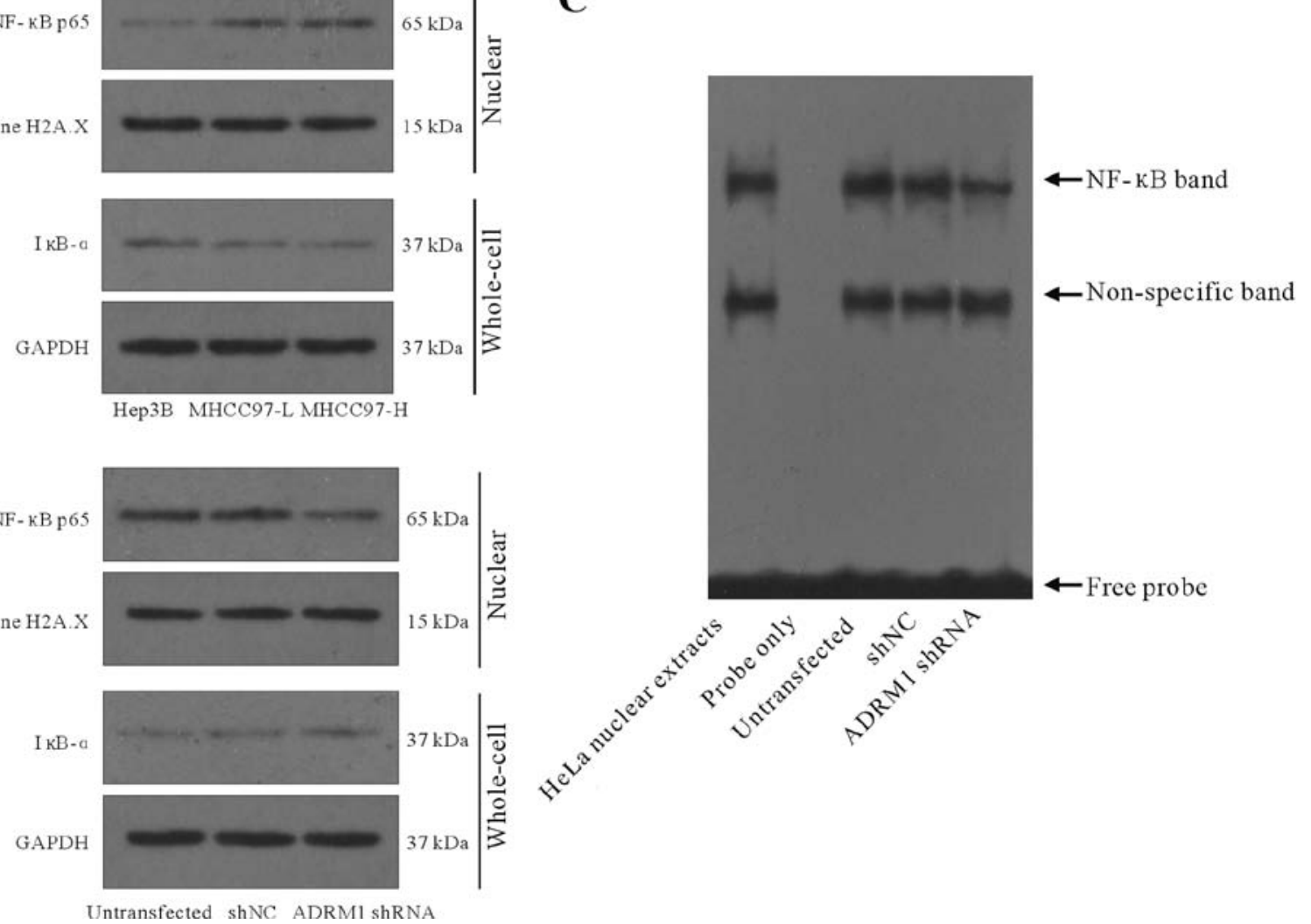

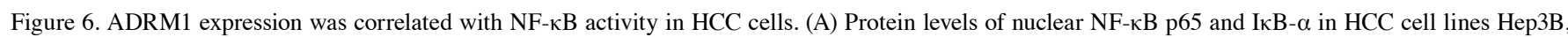
MHCC97-L and MHCC97-H. Histone H2A.X was used as a loading control for nuclear extracts. (B) Effect of ADRM1 knockdown on nuclear NF- $\mathrm{kB}$ p65 and IкB- $\alpha$ protein levels in MHCC97-H cells. (C) Effect of ADRM1 knockdown on NF-кB DNA-binding activity in MHCC97-H cells, as revealed by EMSA assay. Labeled probe without protein was used as a negative control, and HeLa cell nuclear extracts served as a positive control.

Our findings serve as one more piece of supporting evidence for this hypothesis.

As a proteasome-associated protein and a ubiquitin receptor, ADRM1 may be secreted $(7,26)$. It may act through influencing a certain signaling pathway, such as NF- $\kappa \mathrm{B}(27)$, which mediates tumor cells growth, invasion and migration, considering that a persistent NF- $\kappa \mathrm{B}$ activation has been widely observed in $\mathrm{HCC}$ (16-18). In this study, ADRM1 knockdown in MHCC97-H cells increased the expression of $\mathrm{I} \kappa \mathrm{B}-\alpha$ and attenuated the nuclear

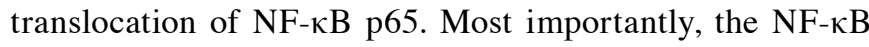
activity in MHCC97-H cells was reduced in response to ADRM1 knockdown. A functional connection between ADRM1 and $\mathrm{NF}-\kappa \mathrm{B}$ in hepatocarcinogenesis is clearly revealed, though the exact mechanisms are still not known. As $\mathrm{I} \kappa \mathrm{B}-\alpha$ functions as a key regulator of $\mathrm{NF}-\kappa \mathrm{B}$ and degradation of $\mathrm{I} \kappa \mathrm{B}-\alpha$ is critically regulated by the $26 \mathrm{~S}$ proteasome degradation pathway (14), a reasonable explanation for our results is that ADRM1 overexpression in $\mathrm{HCC}$ cells enhances I $\kappa \mathrm{B}-\alpha$ degradation, resulting in more nuclear translocation of $\mathrm{NF}-\kappa \mathrm{B}$ p65 and consequently increasing NF- $\kappa \mathrm{B}$ activity.

In conclusion, the overexpression of ADRM1 in $\mathrm{HCC}$ was detected in this study, and it is highly involved in tumorigenic processes of HCC such as proliferation, migration, invasion and apoptosis. A clear connection between ADRM1 and NF- $\kappa$ B in hepatocarcinogenesis was also revealed; an activated $\mathrm{NF}-\kappa \mathrm{B}$ activity in HCC might be the results of enhanced degradation of I $\mathrm{B}-\alpha$ by ADRM1, even though more work is needed to understand the precise mechanisms.

\section{Acknowledgements}

This study was supported by Natural Science Foundation of Hunan Province, China (grant no. 10JJ3055). The authors thank the patients who participated in this study, and all the staff who assisted with the sample collection and pre-treatment in the operation room.

\section{References}

1. Yao T, Song L, Xu W, DeMartino GN, Florens L, Swanson SK, Washburn MP, Conaway RC, Conaway JW and Cohen RE: Proteasome recruitment and activation of the Uch37 deubiquitinating enzyme by Adrm1. Nat Cell Biol 8: 994-1002, 2006.

2. Jørgensen JP, Lauridsen AM, Kristensen P, Dissing K, Johnsen AH, Hendil KB and Hartmann-Petersen R: Adrm1, a putative cell adhesion regulating protein, is a novel proteasome-associated factor. J Mol Biol 360: 1043-1052, 2006.

3. Hamazaki J, Iemura S, Natsume T, Yashiroda H, Tanaka K and Murata S: A novel proteasome interacting protein recruits the deubiquitinating enzyme UCH37 to $26 \mathrm{~S}$ proteasomes. EMBO J 25: 4524-4536, 2006.

4. Qiu XB, Ouyang SY, Li CJ, Miao S, Wang L and Goldberg AL: hRpn13/ADRM1/GP110 is a novel proteasome subunit that binds the deubiquitinating enzyme, UCH37. EMBO J 25: 5742-5753, 2006.

5. Husnjak K, Elsasser S, Zhang N, Chen X, Randles L, Shi Y, Hofmann K, Walters KJ, Finley D and Dikic I: Proteasome subunit Rpn13 is a novel ubiquitin receptor. Nature 453: 481-488, 2008.

6. Simins AB, Weighardt H, Weidner KM, Weidle UH and Holzmann B: Functional cloning of ARM-1, an adhesion-regulating molecule upregulated in metastatic tumor cells. Clin Exp Metastasis 17: 641-648, 1999. 
7. Lamerant $\mathrm{N}$ and Kieda $\mathrm{C}$ : Adhesion properties of adhesionregulating molecule 1 protein on endothelial cells. FEBS J 272: 1833-1844, 2005.

8. Kim T, Ha HI, Kim N, Yi O, Lee SH and Choi Y: Adrm1 interacts with Atp6v0d2 and regulates osteoclast differentiation. Biochem Biophys Res Commun 390: 585-590, 2009.

9. Al-Shami A, Jhaver KG, Vogel P, Wilkins C, Humphries J, Davis JJ, Xu N, Potter DG, Gerhardt B, Mullinax R, Shirley CR, Anderson SJ and Oravecz T: Regulators of the proteasome pathway, Uch37 and Rpn13, play distinct roles in mouse development. PLoS One 5: e13654, 2010

10. Pilarsky C, Wenzig M, Specht T, Saeger HD and Grützmann R: Identification and validation of commonly overexpressed genes in solid tumors by comparison of microarray data. Neoplasia 6 : 744-750, 2004

11. Carvalho B, Postma C, Mongera S, Hopmans E, Diskin S, van de Wiel MA, van Criekinge W, Thas O, Matthäi A, Cuesta MA Terhaar Sive Droste JS, Craanen M, Schröck E, Ylstra B and Meijer GA: Multiple putative oncogenes at the chromosome $20 \mathrm{q}$ amplicon contribute to colorectal adenoma to carcinoma progression. Gut 58: 79-89, 2009.

12. Fejzo MS, Dering J, Ginther C, Anderson L, Ramos L, Walsh C, Karlan B and Slamon DJ: Comprehensive analysis of 20q13 genes in ovarian cancer identifies ADRM1 as amplification target. Genes Chromosomes Cancer 47: 873-883, 2008.

13. Sen R and Baltimore D: Inducibility of kappa immunoglobulin enhancer-binding protein NF-kappa B by a posttranslational mechanism. Cell 47: 921-928, 1986.

14. Karin M, Lawrence T and Nizet V: Innate immunity gone awry: linking microbial infections to chronic inflammation and cancer. Cell 124: 823-835, 2006.

15. Pacifico F and Leonardi A: NF-kappaB in solid tumors. Biochem Pharmacol 72: 1142-1152, 2006.

16. Liu P, Kimmoun E, Legrand A, Sauvanet A, Degott C, Lardeux B and Bernuau D: Activation of NF-kappa B, AP-1 and STAT transcription factors is a frequent and early event in human hepatocellular carcinomas. J Hepatol 37: 63-71, 2002.

17. Tai DI, Tsai SL, Chang YH, Huang SN, Chen TC, Chang KS and Liaw YF: Constitutive activation of nuclear factor kappaB in hepatocellular carcinoma. Cancer 89: 2274-2281, 2000.
18. Chan CF, Yau TO, Jin DY, Wong CM, Fan ST and Ng IO: Evaluation of nuclear factor-kappaB, urokinase-type plasminogen activator, and $\mathrm{HBx}$ and their clinicopathological significance in hepatocellular carcinoma. Clin Cancer Res 10: 4140-4149, 2004.

19. Pikarsky E, Porat RM, Stein I, Abramovitch R, Amit S, Kasem S, Gutkovich-Pyest E, Urieli-Shoval S, Galun E and Ben-Neriah Y: NF-kappaB functions as a tumor promoter in inflammationassociated cancer. Nature 431: 461-466, 2006.

20. Haybaeck J, Zeller N, Wolf MJ, Weber A, Wagner U, Kurrer MO, Bremer J, Iezzi G, Graf R, Clavien PA, Thimme R, Blum H, Nedospasov SA, Zatloukal K, Ramzan M, Ciesek S, Pietschmann T, Marche PN, Karin M, Kopf M, Browning JL, Aguzzi A and Heikenwalder M: A lymphotoxin-driven pathway to hepatocellular carcinoma. Cancer Cell 16: 295-308, 2009.

21. Livak KJ and Schmittgen TD: Analysis of relative gene expression data using real-time quantitative PCR and the 2(-Delta Delta C(T)) method. Methods 25: 402-408, 2001

22. Schmittgen TD and Livak KJ: Analyzing real-time PCR data by the comparative C(T) method. Nat Protoc 3: 1101-1108, 2008

23. Chen Q, Gong B, Mahmoud-Ahmed AS, Zhou A, Hsi ED, Hussein M and Almasan A: Apo2L/TRAIL and Bcl-2-related proteins regulate type I interferon-induced apoptosis in multiple myeloma. Blood 98: 2183-2192, 2001.

24. Li Y, Tang ZY, Ye SL, Liu YK, Chen J, Xue Q, Chen J, Gao DM and Bao WH: Establishment of cell clones with different metastatic potential from the metastatic hepatocellular carcinoma cell line MHCC97. World J Gastroenterol 7: 630-636, 2001.

25. Chen W, Hu XT, Shi QL, Zhang FB and He C: Knockdown of the novel proteasome subunit Adrm1 located on the 20q13 amplicon inhibits colorectal cancer cell migration, survival and tumorigenicity. Oncol Rep 21: 531-537, 2009.

26. Wang P, Mariman E, Keijer J, Bouwman F, Noben JP, Robben J and Renes J: Profiling of the secreted proteins during 3T3-L1 adipocyte differentiation leads to the identification of novel adipokines. Cell Mol Life Sci 61: 2405-2417, 2004

27. Mazumdar T, Gorgun FM, Sha Y, Tyryshkin A, Zeng S, Hartmann-Petersen R, Jørgensen JP, Hendil KB and Eissa NT: Regulation of NF-kappaB activity and inducible nitric oxide synthase by regulatory particle non-ATPase subunit 13 (Rpn13). Proc Natl Acad Sci USA 107: 13854-13859, 2010. 